\title{
Headache and Herbal Medicine: An Ethno-botanical Study of Shahrekord, Southwest of Iran
}

\author{
Saber Abbaszadeh ${ }^{1}$, Nima Karami ${ }^{2}$, Fariba Bahmani ${ }^{3}$, Naser Abbasi ${ }^{3 *}$ \\ ${ }^{1}$ Department of Biochemistry, Babol University of Medical Sciences, Babol, Iran \\ ${ }^{2}$ Medical Plants Research Center, Basic Health Sciences Institute, Shahrekord University of \\ Medical Sciences, Shahrekord, Iran \\ ${ }^{3}$ Biotechnology and Medicinal Plants Research Center, Ilam University of Medical Sciences, Ilam, \\ Iran
}

\section{Article Info}

*Correspondence to:

Naser Abbasi

ilamfarma@gmail.com

\section{Article History:}

Received: 23 August 2019

Accepted: 17 Oct 2019

ePublished: : 03 April 2019

Keywords: Neurological diseases, Headache, Ethnobotany, Shahrekord, Iran
Abstract

Chronic pain is a common problem that affects the quality of life of patients. Among chronic pains, headache is one of the most common pains. This study is an ethnobotanical study of headache treatment using medicinal plants in Shahrekord region, Chaharmahal and Bakhtiari province. This study was performed by collecting data using an ethnobotanical questionnaire. Data collection was conducted from 21 April 2017 to 19 February 2018 among 29 traditional therapists. Out of 29 people, 8 were female and 21 male. The results of this study showed that according to the ethnobotanical knowledge of Shahrekord, nine medicinal plant species consisting of Salvia haydragea DC., Astragalus hamosus L., Hyoscyamus kotschyanus Pojark, Hypericum scabrum L., Valeriana officinalis, Origanum vulgare L., Anthemis hyalina DC., Adianthum capillus-veneris L, and Dracocephalum multicaule Montbr \& Auch belonging to a total of 7 families are used in treating headache. The highest frequency of use was obtained for Salvia haydragea DC. (6\%) and Anthemis hyalina DC. (6\%). Most plants with anti-headache effect ( $n$ : 3) belong to the Lamiaceae family, and the aerial parts (38\%) are the most frequently used plant organ for this purpose.This study can provide comprehensive data on clinical remedies based on centuries of experience in the field of headache and thus might lead to perform further clinical trials of these remedies for the treatment of cephalic pain.

How to cite this paper

Abbaszadeh S, Karami N, Bahmani F, Abbasi N, Headache and herbal medicine: An ethnobotanical study of Shahrekord, Southwest of Iran. Plant Biotechnology Persa 2019; 1(1): 10-17. 


\section{Introduction}

Pain is one of the most common phenomena that force people to seek assistance from the healthcare system, thereby affecting their lives [1]. Pain is an unpleasant sensory or emotional experience associated with actual or potential damage, and is classified into two types: acute and chronic [2, 3]. Chronic pain is a common problem that affects the quality of life of people affected. Among chronic pains, headache is one of the most common pains, as more than $90 \%$ of people experience headache for at least one day a year $[4,5]$. The headache may be due to a primary disorder such as migraine, tensile or cluster headaches, or due to a secondary disorder to a systemic disorder or a central nervous system disorder [6]. Many patients with chronic pain, despite drug interventions, continue to experience pain and their quality of life will be significantly affected if they are unable to cope with their pain [7]. Despite the advances in the field of anatomy, physiology, chemical biology, and the production of new drugs, pain remains a significant problem [8]. Headache is one of the most commonly occurring clinical symptoms associated with many diseases. The use of medicinal plants and their therapeutic properties returns to ancient times, but in today's modern and contemporary societies, the medicinal properties of these plants are also used. We have inherited this valuable information mainly from our ancestors generation by generation, and many of them have now been proven by scientific methods; therefore, many of these plants are effective and useful and form the basis of many modern drugs [9-14]. Achieving hidden and undocumented experiences and information is one of the valuable strategies for developing pharmaceutical science and the basis for the production of new drugs. Ethnobotany seeks to retrieve knowledge and traditions that are unwritten and at risk of being extinct.

Maintaining and reflecting these traditional methods is a valuable guide to achieving new drug sources. The purpose of this ethnobotanical study is to investigate headache treatment using medicinal plants in the Shahrekord region in Chaharmahal and Bakhtiari province, Southwest of Iran.

Methodology

Studied region
This study was conducted in Shahrekord, Chaharmahal and Bakhtiari Province, southwest of Iran. Shahrekord is from 50 degrees and 49 minutes and 22 seconds to 50 degrees and 53 minutes and 44 seconds longitude and from 32 degrees and 18 minutes and 22 seconds to 23 degrees and 21 minutes and 50 seconds latitude. Shahrekord is located 97 kilometers southwest of Isfahan. Topographically, Shahrekord is located in the northern section of the Zagros Mountains. With its elevation between 2050 and 2310 meters above sea level, the city is the highest city in Iran and is therefore known as Iran's roof. Shahrekord has a population of 190441 people (55492 households) (Figure 1).

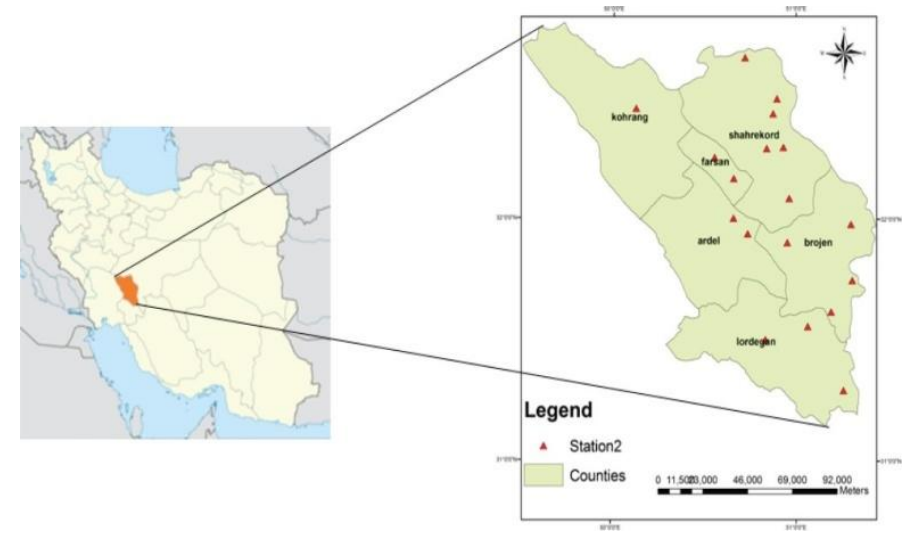

Figure 1. Shahrekord map Data collection procedure

This cross-sectional study was performed by collecting data using an ethno-botanical questionnaire. Data collection was conducted from 21 April 2017 to 19 February 2018 among 29 traditional therapists. The interviewers referred to the 29 therapists in person and administered the questionnaire to them using interview. Out of 29 respondents, 8 were female and 21 male. Their education level was from high school diploma to master's degree. The data extracted from the questionnaires were tabulated consistently. Data analysis was conducted by the Excel software. In this study, the frequency of plant use was calculated by the following formula.

Number of times the plant is used $=$ (Number of people who have mentioned the plant effect divided by total number of people who filled out questionnaires) $\times 100$ 


\section{Results}

Our data analysis showed that according to the ethnobotanical knowledge of Shahrekord, 9 medicinal plant species consisting of Salvia haydragea DC., Astragalus hamosus L., Hyoscyamus kotschyanus Pojark, Hypericum scabrum L., Valeriana officinalis, Origanum vulgare L., Anthemis hyalina DC., Adianthum capillus-veneris L and Dracocephalum multicaule Montbr \& Auch are used in treating headache. Additional information is presented in Table 1.

Table 1. Scientific name, family, Persian name, used organ(s), and frequency of use of medicinal plants used as anti-headache agents in Shahrekord

\begin{tabular}{|c|c|c|c|c|c|}
\hline Scientific name & Herbal family & Local name & $\begin{array}{l}\text { Frequency } \\
\text { of use }\end{array}$ & $\begin{array}{l}\text { Used } \\
\text { organs }\end{array}$ & Treatment \\
\hline Salvia haydragea DC. & Lamiaceae & Gole arvaneh & $6 \%$ & Flower & $\begin{array}{l}\text { Anti- } \\
\text { headache }\end{array}$ \\
\hline Astragalus hamosus L. & Fabaceae & Nakhonak & $3 \%$ & $\begin{array}{l}\text { Aerial } \\
\text { organs }\end{array}$ & $\begin{array}{l}\text { Anti- } \\
\text { headache }\end{array}$ \\
\hline Hyoscyamus kotschyanus Pojark. & Solanaceae & Bang daneh & $1 \%$ & $\begin{array}{c}\text { Seed, } \\
\text { flower, leaf }\end{array}$ & $\begin{array}{r}\text { Anti- } \\
\text { headache }\end{array}$ \\
\hline Hypericum scabrum L. & Hypericaceae & Gole raei & $1 \%$ & $\begin{array}{l}\text { Aerial } \\
\text { organs }\end{array}$ & $\begin{array}{l}\text { Anti- } \\
\text { headache }\end{array}$ \\
\hline Valeriana officinalis & Caprifoliaceae & Sonbolotieb & $3 \%$ & $\begin{array}{l}\text { Aerial } \\
\text { organs }\end{array}$ & $\begin{array}{l}\text { Anti- } \\
\text { headache }\end{array}$ \\
\hline Origanum vulgare L. & Lamiaceae & Marzanjoush & $3 \%$ & $\begin{array}{l}\text { Aerial } \\
\text { organs }\end{array}$ & $\begin{array}{r}\text { Anti- } \\
\text { headache }\end{array}$ \\
\hline Anthemis hyalina DC. & Asteraceae & $\begin{array}{l}\text { Babouneh } \\
\text { kazeb }\end{array}$ & $6 \%$ & $\begin{array}{l}\text { Flower, } \\
\text { stem }\end{array}$ & $\begin{array}{r}\text { Anti- } \\
\text { headache }\end{array}$ \\
\hline Adianthum capillus-veneris $\mathrm{L}$. & Polypodiaceae & Paresiavashan & $3 \%$ & $\begin{array}{l}\text { Aerial } \\
\text { organs }\end{array}$ & $\begin{array}{r}\text { Anti- } \\
\text { headache }\end{array}$ \\
\hline $\begin{array}{l}\text { Dracocephalum multicaule } \\
\text { Montbr \& Auch. }\end{array}$ & Lamiaceae & Zarrin giah & $1 \%$ & Leaf, flower & $\begin{array}{l}\text { Anti- } \\
\text { headache }\end{array}$ \\
\hline
\end{tabular}


The highest frequency of use was obtained for Salvia haydragea DC. (6\%) and Anthemis hyalina DC. (6\%) (Table 1).

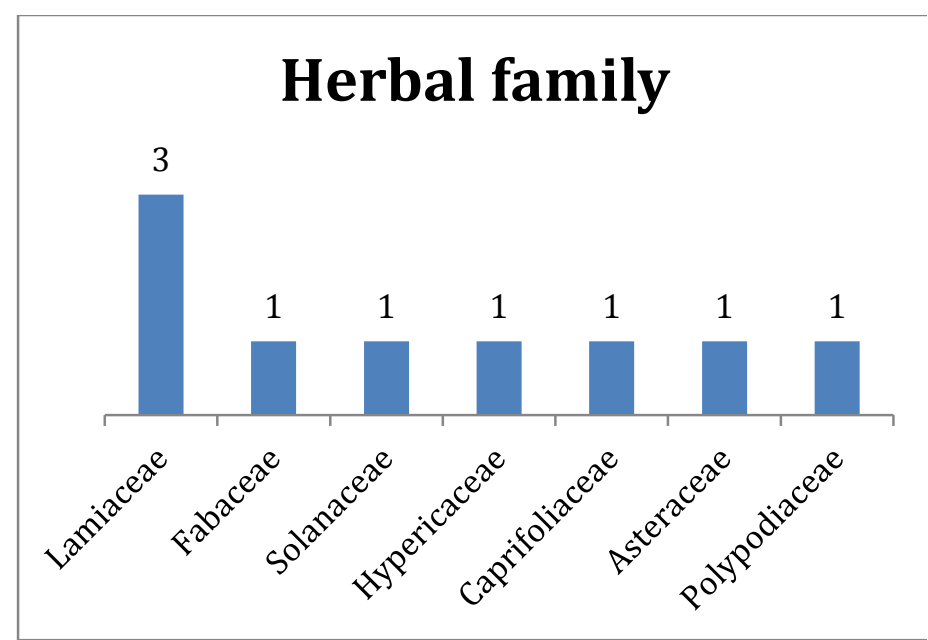

Figure 1. The distribution of anti-headache plant families

\section{Used organs}

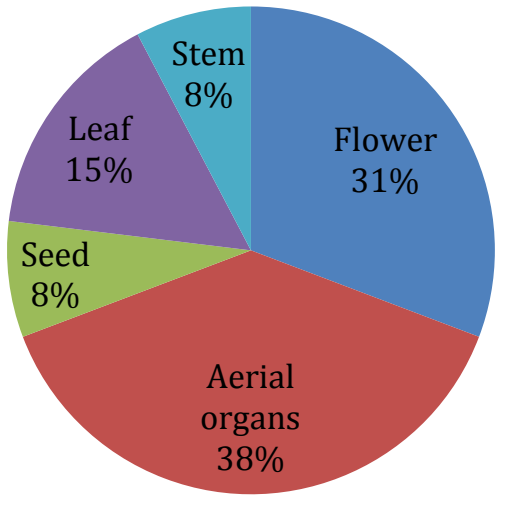

Figure 2. The percentage of plants organs with anti-headache effect

As Figure 1 illustrates, most plants with anti-headache effect (n: 3 ) belong to the Lamiaceae family, and as Figure 2 illustrates, the aerial parts (38\%) are the most frequently used plant organs for this purpose. Additional information is illustrated in Figures 1 and 2.

\section{Discussion}

Headaches are the most common health problem that can be seen in adults, children, and even the elderly. The main cause of headaches is high-risk lifestyle. The headache has different types, such as cluster headaches, migraine headaches, headaches caused by tension and headaches caused by fatigue, all of which are very painful. Physicians and health providers have collected and used ancient knowledge about medicinal plants for treatment of various diseases from other cultures or have gained from their own experiences. Traditional Persian Medicine has presented precise descriptions of headache types from these experiments and knowledge [15].

Herbal medicine has been one of the most usual therapeutic strategies for headache therapy in Traditional Persian Medicine, however, other methods including animal and mineral and synthetic drugs or other strategies such as venesection and cupping have been in focus [16]. The mechanism actions of medicinal plants are not clear however, anti-inflammatory, analgesic, or sedative properties might be the principal way of their actions [17]. It has been shown that more than $60 \%$ of herbal medicines or medicinal plants effective on headache have anti-inflammatory activities. Furthermore, alteration of temperament with plants is another therapeutic strategy in Traditional Persian Medicine to reduce headache [18]. In sum, more researches are needed to clarify the mechanism actions of medicinal plants in treatment of headache disorders.

Besides variety of plants for treatment, route of administration and dosage forms in TPM are interesting. Plants have been prepared and administered as topical, oral, and nasal dosage forms. The most administered dosage form was topical, while ease of application and patient compliance are additional reasons in considering topical dosage forms. In this application, plants were mixed with vinegar, olive oil, rose oil, barley flour, albumen, herbal juices or milk to increase penetration, decrease unwanted effects, or dilute potent substances. Another route for drug administration is nasal application which has been significantly applied in headache treatment in TPM. This route is a potentially alternative route for systemic drug bioavailability in parenteral restricted administration. Easy absorption, rapid onset of action, desirable penetration, avoidance of hepatic first pass effect, and potential for direct drug delivery to the CNS via the olfactory region are some benefits of this kind of drug delivery system which has an important place in modern pharmaceutical sciences. Besides oral or topical application, 47 medicinal plants have been applied nasally for headache 
treatment and specifically 15 medicinal plants were just administered through this route. This amount of nasally cited medicinal herbs can show that this novel route was fully considered by Persian practitioners.

Obviously, there are many possible and available strategies that can lead to develop new and effective headache treatment from medicinal plants. Beside historical clarification, this study can provide comprehensive data on clinical remedies based on centuries of experience in the field of headache and thus might lead to perform further clinical trials of these remedies for the treatment of cephalic pain.

\section{Authors' contribution}

All authors contributed equally to the manuscript.

\section{Conflicts of interest}

The authors declared no competing interests.

\section{Ethical considerations}

Ethical issues (including plagiarism, data fabrication, double publication and etc.) have been completely observed by author.

\section{Funding/Support}

None.

\section{References}

1. Shakeri R, Shaeiri MR, Roshan R. The effect of biofeedback training on experimental pain according to perfectionism. J Psychol 2007; 11(1): 43-59.

2. Jahangiri M, Montazeri K, Mohammadian F. The effect of two types of analgesic suggestion on the reduction of cold pressor pain in hypnotic state. J Anesth Crit Care 2007; 29(57): 52-57.

3. Gatchel RJ, Turk DC. Psychological approaches to pain management: a practitioner's handbook. The Guildford Press; 1996.

4. Breivik H, Collett B, Ventafridda V, Cohen R, Gallacher D. Survey of chronic pain in Europe: prevalence, impact on daily life, and treatment. Eur J Pain 2006; (10): 287-333.

5. Gatchel R, Blanchard EB. Psychophysiological disorders. Washington: Am Psycholog Assoc 1997; 24112.
6. Kolar KR, Fisher W, Gordon V. Nurse my head hurts: a review of childhood headaches. J Sch Nurs 2001; 17(3):120-126.

7. Sadoughi M, Akkashe G. Effectiveness of CognitiveBehavioral Therapy of Reduction of Chronic Tension Headache. J Shahrekord Uni Med Sci 2009; 11(3): 8592.

8. McMahon SB, Koltzenberg M. Textbook of Pain. Elsevier: Churchill: Livingstone; 2006.

9. Behruzian A, Hosseinzadeh Samani B, Rostami S, Lorigooini Z, Behruzian M. The effect of combined AC electric field and ultrasound on the chemical compositions and Escherichia coli content of spearmint aromatic water. J Food Process Engin 2018; 41(2): 12650.

10. Samani BH, Gudarzi H, Rostami S, Lorigooini Z, Esmaeili Z, Jamshidi-Kia F. Development and optimization of the new ultrasonic-infrared-vacuum dryer in drying Kelussia odoratissima and its comparison with conventional methods. Indust Crops Prod 2018; 123: 46-54

11. Rostami S, Behruzian M, Samani BH, Lorigooini Z, Hosseinabadi T, Zareiforoush H, Behruzian A. Study of Combined Ultrasound-microwave Effect on Chemical Compositions and E. coli Count of Rose Aromatic Water. Iranian J Pharmac Res 2018; 17(Suppl2):146.

12. Lorigooini $Z$, Samani $B H$, Zareiforoush $H$. Optimization of the Efficiency of Electromagnetic Waves Dryer Power on Chemical Composition and Yield of S atureja bachtiarica Essential Oil Using Response Surface Methodology. J Essent Oil Bearing Plants 2017; 20(1): 1-1.

13. Samani BH, Lorigooini Z, Zareiforoush H, Jafari S. Effect of ultrasound and infrared drying methods on quantitative and qualitative characteristics of Satureja bachtiarica essential oil. J Essent Oil Bearing Plants 2017; 20(5):1196-208.

14. Hosseinzadeh Samani B, Behruzian A, Behruzian M, Rostami S, Wibowo JP, Mobini G, Lorigooini Z. The Effect of Combined AC Electric Field-Ultrasound on Pasteurization and Chemical Compositions of Rose Aromatic water. J Essent Oil Bearing Plants 2018; 21(6): 1493-510. 
15. Zarshenas MM, Petramfar P, Firoozabadi A, Moein MR, Mohagheghzadeh A. Types of headache and those remedies in traditional persian medicine. Pharmacogn Rev 2013; 7(13): 17-26.

16. Ibn Sina. Persian translated by A. Sharafkandi. Vol. 1. Tehran: Soroush Press. Canon Med 2005; 1024.

17. Gorji A, Khaleghi Ghadiri M. History of headache in medieval Persian medicine. Lancet Neurol 2002; 1: 510-5.

18. Arzani MA. Tebb-e-Akbari Vol. 1. Tehran: Jalal-aldin Press. Akbar's Medicine, 2008. 